\title{
Medication Compliance Aids Unpackaged: A National Survey
}

\author{
Sharmila Walters ${ }^{1}$, Mollika Chakravorty ${ }^{1}$, Sophie McLachlan ${ }^{1}$, Jessica Odone ${ }^{1}$, Jennifer \\ Stevenson $^{2}$, John Minshull ${ }^{3}$, and Rebekah Schiff ${ }^{1}$ \\ ${ }^{1}$ Guy's and St Thomas' NHS Foundation Trust \\ ${ }^{2}$ King's College London \\ ${ }^{3}$ Northwick Park Hospital
}

June 27, 2021

\begin{abstract}
Background: 64 million pharmacy filled multicompartment medication compliance aids (MCAs) are dispensed by pharmacies in England each year as a method to improve medication adherence. Despite the widespread use of MCAs and evidence that their use may be associated with harm there is no national consensus regarding MCA provision by acute hospital Trusts in England. Aim: To determine current practice for initiation and supply of MCAs in acute hospital Trusts in England and the potential consequences for patients and hospitals. Methods: A 26 item survey was distributed to all acute hospital Trusts in England. The questionnaire covered policy, initiation, supply and review of MCAs; alternatives offered; and pharmacy staffing and capacity related to MCAs. Results: 72 out of 138 (52\%) Trusts responded to the survey. 60/70 (86\%) had a policy for the provision of MCAs. 33/55 (60\%) that supplied MCAs on discharge supplied a different prescription length for MCA vs. non-MCA prescriptions. 49/55 (89\%) Trusts provided only one brand of MCA. 47/55 (85\%) MCA-supplying Trusts identified frequent difficulties with MCAs and 13/55 (24\%) reported employing staff specifically to complete MCAs. 30/35 (86\%) MCAinitiating Trusts had an assessment process for initiation, with care agency request as the most common reason. Conclusion: There is a lack of a national approach to MCA provision and initiation by acute hospital Trusts in England. This leads to significant variation in care and has the potential to put MCA users at an increased risk of medication related harm.
\end{abstract}

\section{Hosted file}

Medication Compliance Aids Unpackaged A National Survey.docx available at https://authorea. com/users/422290/articles/528027-medication-compliance-aids-unpackaged-a-national-survey 

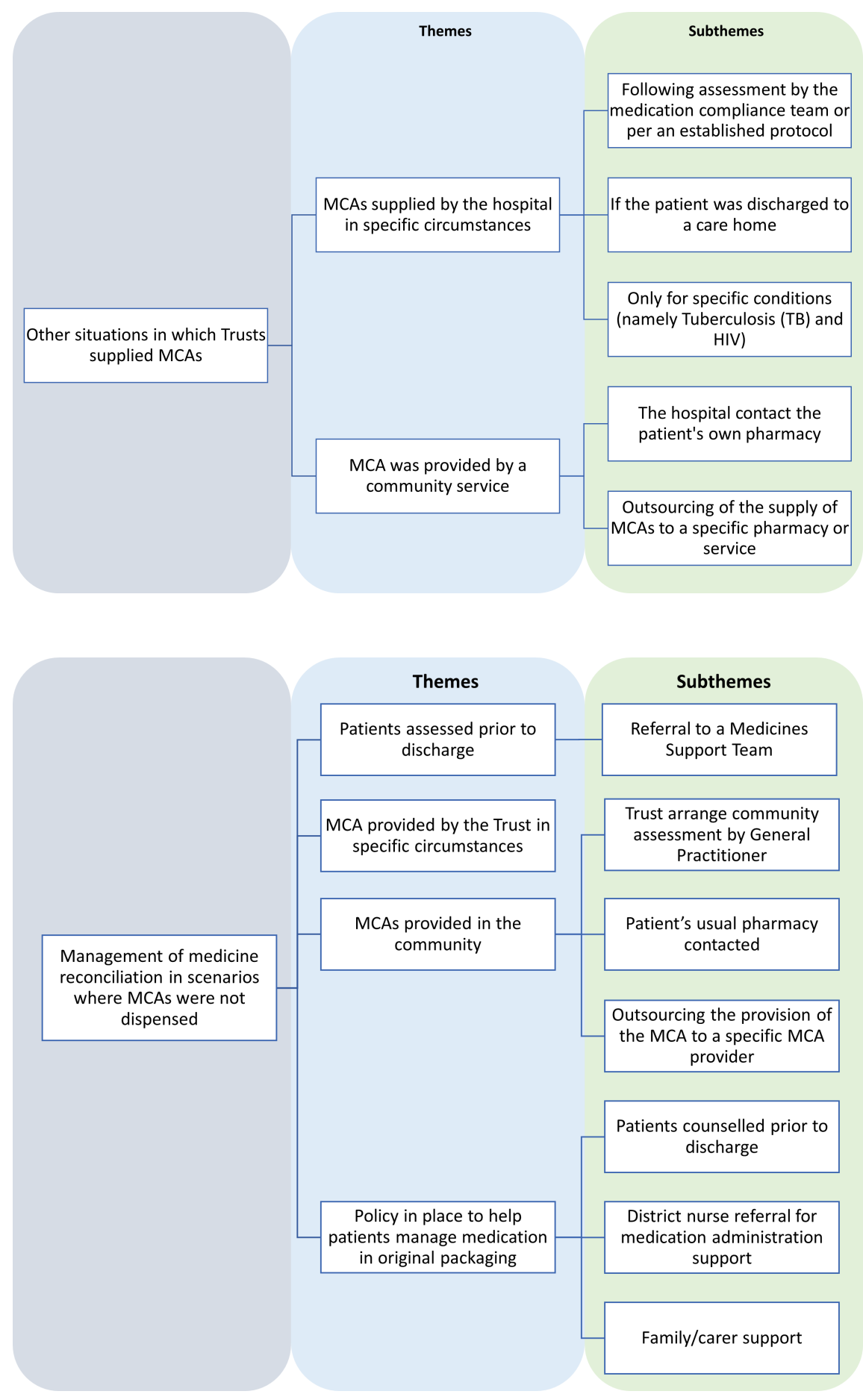
Problems related to MCAs (in last week)

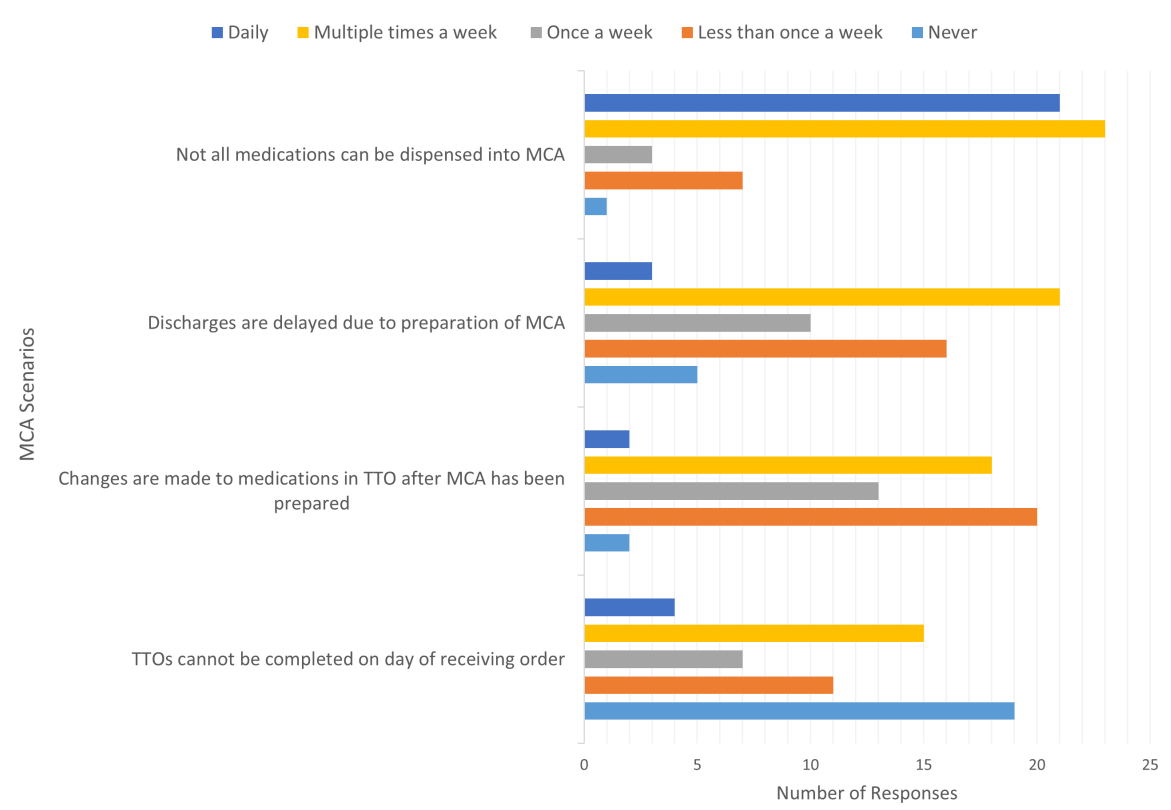

Pharmacy perception on how often reviews of MCAs are completed

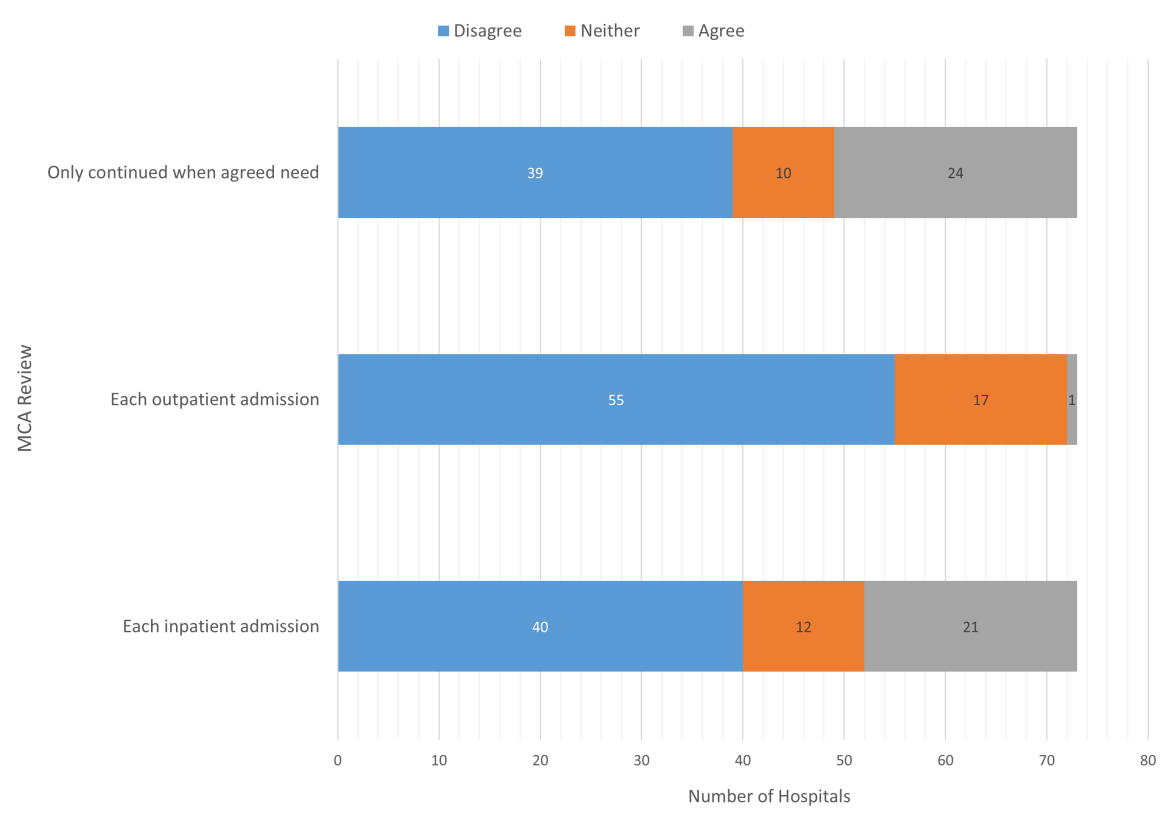

